\title{
MOMENTOS DE AVALIAÇÃO E MOVIMENTOS DE MUDANÇA EM UM CURSO DE FARMÁCIA
}

\author{
Eula Maria de Melo Barcelos Costa* \\ Maria Teresa Freitas Bara** \\ Telma Alves Garcia***
}

Recebido: 3 dez. 2011

Aprovado: 3 ago. 2012

* Curso de Farmácia da Universidade Federal de Goiás. Goiânia, GO, Brasil.
Contato com a autora: eulamm@gmail.com
** Curso de Farmácia da Universidade Federal de Goiás. Goiânia, GO, Brasil.
Contato com a autora: mbara@farmacia.ufg.br
*** Curso de Farmácia da Universidade Federal de Goiás. Goiânia, GO, Brasil.
Contato com a autora: telmagar2@gmail.com

Resumo: Os processos avaliativos do curso de graduação em farmácia da Universidade Federal de Goiás se iniciaram a partir do Programa de Avaliação Institucional das Universidades Brasileiras (PAIUB). Em seu percurso, têm sido empregadas diferentes metodologias visando a evolução do processo e a agregação de diferentes olhares que, ao longo do tempo, vêm contribuindo para a busca da excelência do curso. Considerando concepções e enfoques de estudantes, professores, servidores técnico-administrativos e especialistas em avaliação, foi possível vislumbrar mudanças que progressivamente vêm permeando o curso. As possibilidades e expectativas apontam para a incorporação de novas vivências por parte dos docentes, com práticas pedagógicas diversificadas, bem como dos estudantes, com novas relações sociais.

Palavras-chave: Avaliação de curso. Avaliação institucional.

\section{EVALUATION MOMENTS AND CHANGE MOVEMENTS IN A PHARMACY PROGRAM}

Abstract: The evaluation processes in the undergraduate pharmacy program at Universidade Federal de Goiás started with the Program of Institutional Evaluation of the Brazilian Universities. During this period, different methods have been applied aiming to develop the process and add different perspectives, which have been contributing to achieve academic excellence. Taking into consideration the concepts and approaches of students, professors, technical and administrative personnel, and evaluation specialists, it was possible to detect changes which have gradually been permeating the program. The possibilities and expectations point to the incorporation of new practices by the professors, with diversified pedagogical activities, as well as by the students, with new social relationships.

Key words: Program evaluation. Institutional evaluation.

\section{INTRODUÇÃO}

Através de uma boa avaliação pessoas e instituições reconhecem seus limites e possibilidades; reconhecem o que necessita ser superado e o que pode ser estimulado ou criado na perspectiva de uma forma adequada de gerenciar afazeres, quer seja no aspecto individual, coletivo ou na gestão de organizações de trabalho de toda natureza. 
No passado uma formação mais humanista em Farmácia foi pouco valorizada e os cursos tinham caráter fortemente tecnicista e profissionalizante. A partir de 1987 mobilizações nacionais iniciadas no meio estudantil e encampadas pelas diversas entidades de classe, originaram documentos e propostas para a formação de um novo profissional com competências para visão sistêmica, compreensão do todo, capaz de mobilizar e integrar conhecimentos para uma atuação mais assertiva (RIOS, 2011). Isso exige flexibilidade e adaptação pessoal, profissional, institucional e social. Um longo caminho vem sendo trilhado, perseguindo as mudanças necessárias para se atingir o perfil desejado.

\section{MEMÓRIAS}

Iniciado em 1948, o curso de Farmácia da Universidade Federal de Goiás (UFG) não detém registros de atividades avaliativas até o início do Programa de Avaliação Institucional das Universidades Brasileiras, o PAIUB. Este programa criado em 1994 pela Secretaria do Ensino Superior do Ministério da Educação (SESU/MEC), resultou da implantação de uma proposta da Associação Nacional dos Dirigentes das Instituições Federais de Ensino Superior - Andifes (BADAN, 1997). Neste contexto, o primeiro projeto de avaliação institucional da UFG teve inicialmente como área de abrangência o ensino de graduação, tomado como foco do processo, pois, conforme Severino (2009) o núcleo mais forte da vida universitária, é esse nível de ensino.

O curso de Farmácia da UFG aderiu prontamente ao processo, sendo objeto de avaliação a resolução curricular vigente e o desenvolvimento das atividades inerentes ao curso. Foram coletados dados por meio dos instrumentos: Avaliação da Disciplina pelo Aluno, Avaliação da Disciplina pelo Docente, Avaliação do Curso pelo Aluno (formando) e Avaliação do Curso pelo Docente, todos contemplando questões fechadas e abertas. Para a análise da resolução curricular foi constituída uma comissão composta por: especialistas da UFG, representante estudantil, representante dos servidores técnico-administrativos, professores e pelo coordenador do curso. Após a divulgação dos resultados seguiu-se um seminário onde foram apreciados a estrutura curricular, os objetivos do curso e o resultado geral das avaliações.

Na perspectiva dos professores e estudantes destacaram-se:

Um índice de titulação docente razoável em comparação com a média da UFG e priorização ao ensino e às atividades administrativas e de extensão em detrimento das atividades de pesquisa. [...]. Por outro lado, os alunos assinalam uma defasagem com relação ao 
perfil profissional exigido pelo mercado [...]. Os dados referentes à infraestrutura indicam necessidade de melhorias em alguns aspectos, principalmente equipamentos de informática e restaurantes. A existência representativa de sugestões para a melhoria de aspectos didático-pedagógicos conduz à necessidade de se discutir o tema, assim como indica necessidade de reforma curricular (BADAN, 1997, p. 212-213).

Por sua vez, a Comissão de Análise da Resolução Curricular do curso registrou:

A integração entre ensino, pesquisa e extensão se dá através da atividade docente assistencial no Laboratório de Análises Clínicas, na Farmácia de manipulação e de pesquisas emergentes [...]. Não há na resolução curricular definição clara do perfil do núcleo central. Há necessidade ainda da reestruturação das habilitações e criação de Farmácia Escola. [...] foi citado que não existe fluxo de informações entre o ciclo básico e o profissionalizante o que resulta em falta de integração entre os dois níveis (BADAN, 1997, p. 213).

Na mesma perspectiva, no relatório resultante do seminário de autoavaliação realizado pelo curso de Farmácia no final de 1996, prévio ao II Seminário de Avaliação Institucional da UFG, foi ressaltado "consideramos o evento de grande valor num momento onde as Faculdades de Farmácia do Brasil aguardam ansiosamente a Resolução que fixará um novo currículo mínimo para o curso" (BADAN, 1997, p. 214). Foi consenso a necessidade de reformulação curricular, mas julgou-se oportuno aguardar a regulamentação de uma proposta que já se encontrava na Comissão de Ensino Farmacêutico do então Ministério de Educação, Cultura e Desporto.

Foram citadas como limitações às adequações e expansão do curso, o espaço físico disponível e a defasagem no número de professores, esta última atribuída às aposentadorias e ausência de criação de novas vagas. Em referência ao processo de avaliação vale citar o seguinte pronunciamento: "sentimos a falta de participação de um maior número de pessoas [...] o que pode ser atribuído à falta de conhecimento da importância da avaliação institucional [...], que foi um grande momento em nossa vida acadêmica [...]." (BADAN, 1997, p. 217).

Seguiu-se uma avaliação externa do curso procurando-se relacionar a pesquisa, a extensão e a gestão acadêmica à graduação. Esta etapa apresentou como finalidade, segundo a Comissão de Avaliação Externa (CAE), "subsidiar, através de uma visão crítica e imparcial de seus membros, a Faculdade de Farmácia no sentido de conhecer suas dificuldades, limitações e potencialidades" 
(UFG, 1997, p. 5). A Comissão, designada pelo Reitor, foi composta por pares acadêmicos e por um farmacêutico representante de serviços que recebem egressos do curso. Orientada pela Comissão de Avaliação Institucional da UFG (CAVI) de que deveria apresentar sugestões visando contribuir para a superação de dificuldades, a CAE também chamou a atenção para a necessidade de reformulação curricular e de maior integração entre o ciclo básico e o profissionalizante. Destacou-se como aspectos bastante positivos, o contato dos estudantes com a realidade profissional por meio dos estágios curriculares e a busca da titulação docente. Sugeriu-se a criação de algumas linhas de pesquisa visando ao aumento da produção científica e à implantação de um programa de pós-graduação stricto-sensu e enfatizou "[...] é importante resgatar o papel do farmacêutico como profissional da saúde, oferecendo-lhe uma formação que permita sua inserção na comunidade [...] a formação oferecida não contempla a área humanística" (UFG, 1997, p. 9). Ao mesmo tempo, a Comissão recomendou uma adequação do currículo à realidade regional com aprofundamento de conteúdos nas áreas de gestão e planejamento. Ressaltou a importância da elaboração de trabalho de conclusão de curso (TCC) a exemplo do que ocorria na habilitação Farmácia-Bioquímica, modalidade Análises Clínicas e sugeriu a extensão dessa atividade para as demais habilitações do curso. Foi foco de atenção o baixo índice de evasão e retenção e, na área administrativa, a necessidade de um sistema mais ágil para agrupamento e processamento de informações institucionais: "os dados existem, mas são encontrados de forma isolada [...]" (UFG, 1997, p. 13). Na conclusão do relatório foi expresso:

O curso de Farmácia no Brasil como um todo tem vivido um momento de discussão com o objetivo de traçar as Diretrizes Básicas do Ensino Farmacêutico. Este processo tem reflexos na própria Faculdade de Farmácia da UFG, impedindo de alguma forma uma adequação mais rápida do curso à realidade regional e nacional (p. 16).

Este foi um período marcante para os gestores do curso que passaram a compreender a importância e contribuição da avaliação para a análise do conjunto de atividades e processos desenvolvidos numa instituição de ensino, com vistas à superação de pontos inconsistentes. Tendo participado de todas as etapas do programa de avaliação implantado, tão logo tomaram conhecimento dos resultados partiram em busca de soluções. Elegeram prioridades, e dentre estas optaram por atender a principal reivindicação do corpo discente. Tratava-se da implantação de uma farmácia universitária que abrangesse as diferentes atividades possíveis no âmbito de uma farmácia. Assim, foi criada a Farmácia 
Escola que projetada e administrada conforme os rigores de uma Instituição de Ensino Superior (IES) logo se tornou referência nacional servindo de modelo para projetos semelhantes em outras IES do país.

\section{NOVOS CAMINHOS}

No início de 1998 uma nova equipe de gestores assumiu a condução da UFG. Ao mesmo tempo, foi deflagrada uma greve nas IES federais que se estendeu por longo período, comprometendo as atividades de avaliação. No ano seguinte, recomposta a CAVI e constatada a necessidade de redirecionamento metodológico, foi elaborado outro projeto de avaliação para a Universidade, denominado de Avaliação Institucional: uma mudança em curso. Neste, agregou-se o cumprimento de metas definidas em planejamento coletivo por professores, servidores técnico-administrativos e estudantes. Partiu-se do princípio de que, quando o planejamento é coletivo, coletivos também serão os encargos, as obrigações decorrentes e os compromissos com a sua execução (COSTA, 2010).

O fechamento do ciclo avaliativo nesse novo projeto considerava o cumprimento das etapas: planejamento estratégico, autoavaliação realizada por docentes, discentes e técnico-administrativos e avaliação externa. A metodologia adotada foi a do grupo focal, acrescida de indicadores quantitativos existentes nos sistemas de informação da UFG (UFG, 2002). Buscou-se a visão do todo sob novos ângulos, como expresso na visão de Minayo (2009, p. 87).

A técnica dos grupos focais passou a ocupar um lugar fundamental em investigações qualitativas no campo social, cultural, psicológico, organizacional, educacional e da avaliação. O grupo permite manifestar divergências, explicitar e defender pontos de vista, mas também mudar de opinião.

A Faculdade de Farmácia, vislumbrando oportunidade de avançar em seus propósitos, foi a primeira dentre as unidades acadêmicas e órgãos da UFG, a manifestar oficialmente seu interesse em participar desse novo momento da avaliação. Convicta da necessidade e do "poder transformador" pedagógico, realizou seu primeiro planejamento estratégico em 2000. Entendeu que com planejamento, ações bem intencionadas, porém dispersas, podem convergir para ações coordenadas e definidas que resultem em medidas concretas, capazes de otimizar esforços para a obtenção de sucesso na concretização de objetivos. Definiu como missão: Formar farmacêuticos competentes, capacitados, 
atualizados e cientes da necessidade de socialização do conhecimento para a formação de uma sociedade melhor; ética e justa. E como visão: Ser uma unidade modelo na Universidade Federal de Goiás, escola de referência no ensino farmacêutico do país e ser reconhecida como tal.

Avaliações rotineiras começaram a acontecer, mesmo não sendo percebido prontamente que determinadas atitudes nada mais eram que: avaliações, reavaliações, pequenos replanejamentos e consecução de metas.

O período compreendido entre o final de outubro de 2001 e janeiro de 2002 foi destinado à avaliação oficial, com a realização dos diferentes grupos focais. Foram objetos de discussão: o cumprimento das metas traçadas, o comprometimento da unidade acadêmica, o ensino, a pesquisa, a extensão, a gestão e a nova dinâmica do processo de avaliação. No grupo constituído por estudantes foram priorizadas as questões: motivo da escolha do curso, estrutura curricular, procedimentos didáticos e de avaliação da aprendizagem, relações interpessoais em suas diversas vertentes, gestão do curso e a dinâmica do processo de avaliação.

Os avaliadores que compuseram o grupo focal externo foram profissionais da área farmacêutica, ex-professores do curso, empresários ligados ao setor farmacêutico, representantes de classe e de órgãos fiscalizadores. Neste grupo as questões balizadoras foram: como viam a Faculdade de Farmácia? Como era a relação de sua instituição/empresa com a Faculdade? Qual a percepção sobre o ensino, a pesquisa, a extensão e sobre essa nova forma de realizar avaliação?

Concluídos os relatórios dos diferentes grupos o mediador do grupo dos professores ressaltou as percepções:

A falta de uma cultura de avaliação [...] revela a necessidade de se investir mais na sensibilização para o processo e na otimização do monitoramento. A maioria das metas foi cumprida. A atual gestão, a coesão grupal e o compromisso de corpo e alma de um grupo significativo, foram considerados os fatores facilitadores para isto. $\mathrm{O}$ caráter processual de certos itens, a falta de recursos financeiros da Universidade Pública, a falta de um comprometimento maior foram razões colocadas para o não cumprimento total das metas. $\mathrm{O}$ ensino tem melhorado, particularmente pelo investimento em recursos técnicos e em capacitação docente. A pesquisa foi considerada o ponto fraco [...] a Faculdade só tem recém-doutores. A extensão foi considerada um dos pontos fortes [...] tem contribuído com a melhoria do ensino. A gestão foi muito bem avaliada [...] no avanço que a Faculdade vem experimentando (UFG, 2002, p. 122-123). 
No grupo dos servidores técnico-administrativos o mediador transcreveu o que considerou ser a expressão geral do grupo:

A maioria das metas da Faculdade de Farmácia foi cumprida. As que não foram concluídas tiveram como obstáculo a escassez de pessoal e a falta de recursos financeiros. As relações interpessoais entre todos os segmentos são boas (UFG, 2002, p. 129-130).

O mediador do grupo dos estudantes registrou que "mesmo sem existir consenso ou com opiniões antagônicas os alunos de forma geral aprovam o curso". Demonstraram seu descontentamento com o acúmulo de atividades e transtornos gerados por greves na instituição. A maior parte das discussões foi centrada em sugestões de redistribuição ou inclusão de novas disciplinas na matriz curricular. Na visão dos estudantes, os professores utilizavam bem os recursos didáticos e na opinião de alguns, o professor que diversificava a metodologia de ensino era visto como "[...] o professor não dá aula, divide os grupos e os alunos apresentam seminários".

As discussões realizadas pelos avaliadores externos foram bastante profícuas e abrangentes. A mediadora do grupo sintetizou nas seguintes observações:

A Faculdade de Farmácia tem profissionais e produtos muito bons, mas faltam-lhes divulgação, o que aliás foi estendido a toda a Universidade. Falta desenvolver parcerias internas (entre unidades da UFG). É necessária uma reformulação curricular. O professor está distanciado da realidade profissional [...]. É necessário repensar o sistema de avaliação escolar. A Faculdade hoje está bem melhor do que há alguns anos (UFG, 2002, p. 147).

No planejamento coletivo seguinte, realizado no ano de 2003, ficou consolidado o entendimento dos benefícios que advém de trabalhos dessa natureza. $\mathrm{O}$ ciclo planejamento/avaliação se repetiu, nos mesmos moldes. Ações importantes foram desenvolvidas e metas se concretizaram, basta citar, a implantação de nova estrutura curricular em 2004, em consonância com as Diretrizes Curriculares Nacionais (Resolução CNE n. 02 de 19 de fevereiro de 2002) e com o recém- aprovado, Regulamento Geral dos Cursos de Graduação da UFG. Em 2005 iniciou-se um Programa de Pós-Graduação Stricto sensu em Ciências Farmacêuticas.

O Sistema Nacional de Avaliação da Educação Superior - Sinaes, adotado pelo Governo Federal (SINAES, 2004) trouxe vertentes que vieram ao encontro do projeto Avaliação Institucional: uma mudança em curso, no sentido de 
corroborá-1o, pois, seus princípios foram coincidentes. À época a UFG estava implantando um Programa de Gestão Estratégica (PGE) articulando planejamento/avaliação/informação. No que se refere à avaliação, foram agregados mais dois instrumentos aos grupos focais: um questionário on-line disponibilizado aos estudantes em períodos pré-definidos para autoavaliação do ambiente acadêmico e outro, disponibilizado a um comitê avaliador interno de cada unidade acadêmica/órgão abrangendo as diversas dimensões do Sinaes.

Com este formato, os múltiplos instrumentos permitiram uma visão mais abrangente e foram geradas informações de grande valia para a gestão da Instituição, tanto no nível micro como no macro. Assim, surgiu o processo atual:

\section{Avaliação como instrumento de gestão.}

No novo contexto como se posicionou o Curso de Farmácia? Em busca de um saber mais amplo sobre si mesmo, em busca da qualidade, sendo esta entendida como efetivação do êxito das metas institucionais conforme refere Bertolin (2009, p. 128): "A alta qualidade institucional está na explícita exposição de sua missão ou objetivos e na eficiência e efetividade no cumprimento das metas autodeterminadas." E qualidade também entendida, como transformação capaz de provocar no estudante a aprendizagem de novos valores e atitudes (HARVEY; GREEN, 1993).

\section{DIFERENTES OLHARES, OUTRAS PERCEPÇÕES}

Sob a ótica do sistema oficial, no final de 1996 o MEC criou o Exame Nacional de Avaliação de Cursos - ENC (Provão) que vigorou até 2003. Consistia em se aplicar uma prova aos concluintes de cursos de graduação, no intuito de avaliar o desempenho cognitivo do estudante. Durante os oito anos em que o Provão vigorou, o Curso de Farmácia da UFG foi avaliado em três momentos: em 2001, 2002 e 2003 e os concluintes do Curso apresentaram desempenho A, B e B respectivamente. Na era Sinaes, o desempenho dos estudantes é avaliado por meio do Exame Nacional de Desempenho do Estudante (Enade) gerando um conceito estratificado em cinco categorias, onde o conceito máximo é 5 (cinco). Ao final do primeiro e do segundo ciclo avaliativo dos cursos de Farmácia, 2007 e 2010 respectivamente, os acadêmicos de Farmácia da UFG obtiveram conceito máximo.

Construindo a reestruturação curricular iniciada em 2004 foram tomadas atitudes ousadas, se considerada a formação do corpo docente da época, no sentido de resgatar o lugar insubstituível do farmacêutico na área da saúde pública. Uma das principais inovações foi a introdução de novos temas nessa 
área de estudos. Em sequência, houve preocupação constante em se avaliar a pertinência e a repercussão das atividades implementadas.

Nesse percurso o Curso de Farmácia foi selecionado para participar do Programa Nacional de Reorientação da Formação Profissional em Saúde Pró-Saúde, cujo objetivo principal é incentivar transformações do processo de formação, geração de conhecimentos e prestação de serviços à população, para abordagem integral do processo de saúde-doença (BRASIL, 2005). Visa qualificar a formação profissional na área de saúde para melhorar a assistência prestada aos usuários do Sistema Único de Saúde (SUS).

Em mais uma oportunidade o curso somou outro processo avaliativo para agregar novos olhares. Em 2008 aderiu ao projeto da Comissão de Avaliação das Escolas Médicas (CAEM) da Associação Brasileira de Educação Médica (ABEM), denominado: Avaliação de Tendências de Mudanças nos Cursos de Graduação das Escolas Brasileiras da Área da Saúde (ABEM/CAEM, 2006). Esse projeto visa verificar a integração da escola com os serviços no SUS em todos os níveis de assistência a saúde, para facilitar a construção do conhecimento pelo discente. Propõe a investigação por triangulação de métodos que segundo Minayo (2006), consiste em desdobramentos metodológicos que buscam combinar e cruzar múltiplos pontos de vista, favorecendo a interação crítica e intersubjetiva.

Na primeira etapa desta avaliação, foi aplicado um questionário de autoavaliação respondido de forma coletiva, com representação dos segmentos de professores, estudantes e servidores técnico-administrativos. Este instrumento contempla 05 eixos consonantes com os do Pró-Saúde: projeto pedagógico, abordagem pedagógica, cenário da prática, desenvolvimento docente e mundo do trabalho. Para os vetores de cada eixo foram estabelecidas três alternativas, a primeira contemplando o paradigma flexneriano e a terceira o paradigma da integralidade em saúde. Na figura representativa do conjunto dos eixos e vetores analisada do centro para a periferia, a predominância de respostas no núcleo central denota um curso tradicional, no nível intermediário um curso inovador e no nível mais externo um curso avançado em termos de mudanças curriculares em atendimento às políticas de saúde (LAMPERT et al, 2009).

A plotagem das respostas permitiu o desenho de uma tipologia de tendências e de evidências de mudanças visando atender ao previsto nas Diretrizes Curriculares Nacionais para os Cursos de Graduação em Farmácia (DCNs). A percepção da Faculdade de Farmácia/UFG sobre si mesma ao responder o instrumento de avaliação foi caracterizada como Tipologia A (Fig. 1). 
Figura 1- Figura da roda: percepção do curso de Farmácia /UFG no $1^{\circ}$ momento avaliativo, Tipologia $A$

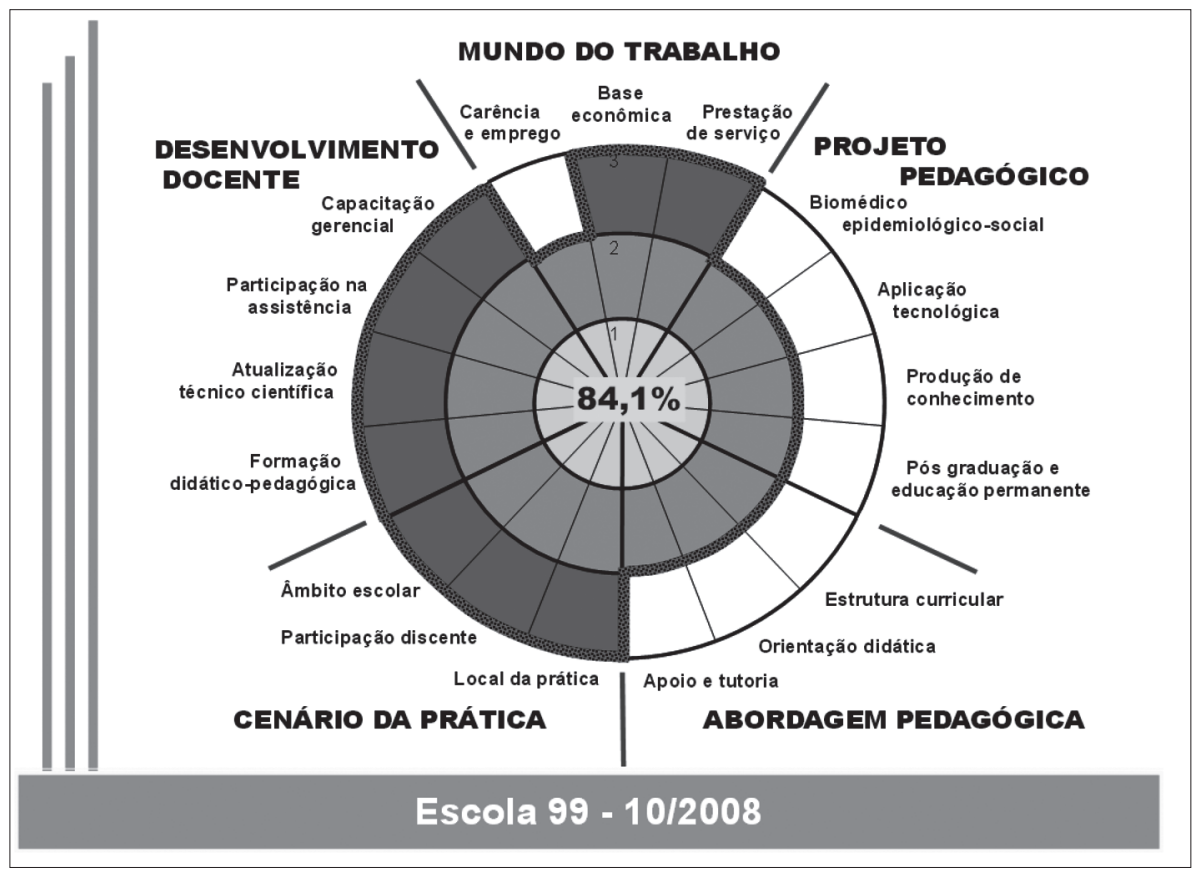

Fonte: COMISSÃO DE AVALIAÇÃO DAS ESCOLAS MÉDICAS (CAEM). Projeto- Avaliação de Tendências de Mudanças nos Cursos de Graduação Brasileiros da Área da Saúde. Relatório: retorno - escola 99, $1^{\circ}$ momento, 2008. p. 6.

Como nos informa Lampert e colaboradores (2009), por tipologia da escola entende-se a tendência de mudança dada pelo conjunto de ações efetivadas e predominantes na implementação do programa curricular do curso de graduação. Pode-se ter: a escola tradicional ou conservadora (T), a inovadora com tendência conservadora ou tradicional (It), a escola inovadora com tendência avançada (Ia) e a avançada (A). Esta denominação evolui, à medida que se efetiva a verdadeira articulação entre o biológico e o social, focando a saúde de forma integral, com abordagem intersetorial, interdisciplinar e mesmo transdisciplinar.

$\mathrm{Na}$ segunda etapa do projeto, foram realizadas oficinas para a construção participativa de indicadores de mudanças. Seguiu-se uma visita externa, in loco em março de 2009, por uma Comissão de Especialistas em Avaliação da Caem. Foram realizados grupos focais com estudantes, professores, gestores de 
serviços de saúde e preceptores, analisados documentos, o Projeto Pedagógico do Curso e realizadas visitas em diferentes campos de prática. A Comissão emitiu um relatório onde registrou suas principais percepções sobre os fatores facilitadores ou não para as mudanças, visando atender às DCNs, especialmente, no que se refere à consolidação do SUS. Transcreveu-se para o relatório a percepção de estudantes quanto às atividades desenvolvidas nos cenários de prática (CAEM, 2009, p. 10):

[...] o mais proveitoso disso é a noção da realidade. Que a gente às vezes, muitas vezes não tem na sala de aula (Estudante). Então a gente realmente trabalhou e não teve nenhum momento assim que a gente ficou desamparada ou só observando as coisas acontecerem. A gente fez mesmo. (Estudante)

Foram considerados pela Comissão fatores facilitadores para as mudanças vislumbradas:

- Existência de núcleo docente estruturante que busca melhorar a estrutura curricular e que deve estar buscando avaliar processos e resultados.

- Parcerias com serviços e diversidade de locais de prática.

- Educação continuada e cursos de especialização que disponibilizam vagas para profissionais dos serviços.

- $5 \%$ da carga horária do curso é integralizada com disciplinas de núcleo livre, realizadas em qualquer unidade acadêmica, para ampliar a visão e flexibilizar o conhecimento.

- A integração ensino/pesquisa/assistência tem ocorrido em estágios e projetos.

Foram elencados como fatores dificultadores:

- Mudança de gestores dos serviços e de políticas públicas.

- Falta de inserção do farmacêutico no programa Estratégia de Saúde da Família.

- Pequeno contingente de professores para realizar orientações nos diversos locais de estágio.

- Redirecionamento do curso para a assistência farmacêutica com pequeno número de docentes com a formação para as novas tarefas que as mudanças exigem. 
Ao concluir o relatório a Comissão emitiu parecer com ponderações como: necessidade de ampliar as metodologias ativas e preparar os docentes para a tutoria; existência de boa carga horária de práticas centradas em habilidades, mas ainda com predomínio de aulas expositivas e provas teóricas; necessidade de revisar o planejamento de inserção e acolhimento dos discentes nos diferentes locais de prática profissional; os processos de avaliação da aprendizagem merecem estudos visando sua adequação e aprimoramento para serem desenvolvidos como recomenda o Projeto Pedagógico do Curso.

Nesse relatório chama a atenção a percepção dos avaliadores sobre a prática pedagógica, o que corrobora a percepção dos estudantes emitida durante a autoavaliação do ambiente acadêmico (2007) onde, 60,5\% dos respondentes informaram que a técnica de ensino usada predominantemente é ainda a aula expositiva tradicional e a prova teórica discursiva é o instrumento de avaliação de escolha para a grande maioria dos professores $(95,0 \%)$ (Tabela 1$)$. Os dados apresentados na tabela 1 mostraram também que, na percepção dos discentes, tem havido boa articulação do trabalho docente e do currículo do curso no que se refere a questões sociais-político-culturais e cotidianas, provavelmente devido aos diferentes cenários de prática a que os alunos são apresentados ao longo do curso.

\section{Tabela 1 - Percentual de respostas dos alunos do curso de Farmácia segundo alguns indicadores de autoavaliação do ambiente acadêmico}

\begin{tabular}{lccccc}
\hline INDICADORES & A & B & C & D & E \\
\hline Articulação com aspectos sociais... $^{\text {a }}$ & 4,2 & 16,0 & 52,1 & 16,0 & 5,0 \\
\hline $\begin{array}{l}\text { Articulação quanto a temas gerais e situa- } \\
\text { ções do cotidiano... }^{\text {a }}\end{array}$ & 6,7 & 31,1 & 49,6 & 2,5 & 3,4 \\
\hline Técnica de ensino $^{\text {b }}$ & 60,5 & 33,6 & 3,4 & 0,0 & 0,8 \\
\hline Instrumento de avaliação $^{c}$ & 95,0 & 3,4 & 0,0 & 0,8 & 0,0 \\
\hline
\end{tabular}

(a) $\mathrm{A}=\mathrm{Sim}$, em todas as atividades do curso; $\mathrm{B}=\mathrm{Sim}$, no ensino de várias disciplinas; $\mathrm{C}=\mathrm{Sim}$, mas apenas no ensino de algumas disciplinas; $\mathrm{D}=$ Não articula; $\mathrm{E}=$ Não sei informar

(b) $\mathrm{A}=$ Aulas expositivas (preleção); $\mathrm{B}=$ Aulas expositivas, com participação dos estudantes; $\mathrm{C}=$ Aulas práticas; $\mathrm{D}=$ Trabalhos de grupo, desenvolvidos em sala de aula; $\mathrm{E}=$ Outra

(c) $\mathrm{A}=$ Provas escritas discursivas; $\mathrm{B}=$ Testes objetivos; $\mathrm{C}=$ Trabalhos de grupo; $\mathrm{D}=$ Trabalhos individuais; $\mathrm{E}=$ Provas práticas

Fonte: Adaptado de (UFG; 2008, p. 14-52). 
Cabe destacar que mesmo antes do recebimento do relatório (CAEM, 2009) com as ponderações emanadas pela Comissão, foram desencadeadas ações que de certa forma vieram contribuir para minimizar ou superar os pontos inconsistentes apontados.

- Contratação de mais docentes para dar suporte às práticas integradas ensino/serviço.

- Criação da Liga Acadêmica Multidisciplinar Farmacêutica.

- Realização de atividades conjuntas ensino e serviço.

- Revisão do Projeto Pedagógico do Curso e início de estudos para nova reestruturação da matriz curricular.

- Análise dos planos de ensino quanto às metodologias de ensino e avaliação da aprendizagem.

- Criação da Rede Goiana de Produção de Conhecimentos Interdisciplinares envolvendo Saúde, Farmácia e Sociedade.

Em setembro de 2009, foi realizada uma oficina de sistematização de dados, terceira etapa desse projeto, onde cada curso participante apresentou e discutiu seu processo de construção autoavaliativa.

Em agosto de 2011, uma equipe de avaliadores do desenvolvimento do projeto Pró-Saúde apontou como objetivo ainda não atingido a contento, a implementação de forma sistemática, de metodologias de ensino mais integrativas. Isto, conforme aponta Cecy; Oliveira; Costa (2010) exigirá dos professores outro nível de envolvimento: capacitação e desenvolvimento docente, reprogramação de afazeres e essencialmente motivação.

\section{CONSIDERAÇÕES FINAIS}

Vivemos num tempo em que as mudanças acontecem com grande rapidez e a educação não pode se furtar a esta realidade. $\mathrm{Na}$ área da saúde os cursos lutam para superar a forma tradicional de organização curricular e pedagógica e evoluir para propostas mais articuladas e orientadas pela prática profissional. Nesse contexto, buscou-se vislumbrar mudanças que progressivamente vem permeando o Curso de Farmácia da UFG. Levou-se em conta concepções e enfoques de estudantes, professores e servidores TA's. A investigação teve como ponto de partida a primeira avaliação situacional realizada no curso. Para tanto, 
utilizou-se análise bibliográfica retrospectiva e a partir de 2007, além da avaliação do ambiente acadêmico, realizada pelos estudantes à época da matricula e incorporada no processo de autoavaliação já existente, buscou-se o olhar com novos desenhos metodológicos articulando diferentes atividades e abordagens de pares acadêmicos, especialistas em avaliação. Estes realizaram análise documental, visitas in loco, novas avaliações. Isto possibilitou aprofundamento nas informações preexistentes, estimulou reflexões e sinalizou novos caminhos.

As análises reflexivas obtidas nesse estudo tem sido compartilhadas com os diferentes envolvidos no processo. Os resultados evidenciam que nos últimos anos as mudanças vêm sendo sustentadas, mesmo com limitações. As possibilidades e expectativas apontam para a incorporação de novas vivências por parte dos docentes com novas práticas pedagógicas e dos estudantes, com novas relações sociais.

Por fim, há que se perguntar por que participar de tantos momentos avaliativos? Nesse sentido, concordamos com Dias Sobrinho (2005) em que a avaliação compreende a busca pela melhoria da qualidade, induzindo as instituições a um contínuo aperfeiçoamento. Propicia aprendizagens coletivas, fortalece compromissos, traz evidências e pode apontar caminhos na busca da excelência. Sendo um processo inacabado as avaliações e os planejamentos continuam, as informações e os diferentes olhares se cruzam e se complementam. Cabe ao Curso de Farmácia rever percepções, refinar o seu olhar e continuar, pelos caminhos da avaliação. Nesse sentido, encontra-se em processo de discussão nova reestruturação curricular que, num futuro breve, terá reflexos na assistência à saúde prestada pelos egressos cujos benefícios repercutirão, de forma inequívoca, tanto na formação dos estudantes quanto na qualidade de vida da população.

\section{REFERÊNCIAS}

ASSOCIAÇÃO BRASILEIRA DE EDUCAÇÃO MÉDICA (ABEM) / COMISSÃO DE AVALIAÇÃO DAS ESCOLAS MÉDICAS (CAEM)

- Projeto de avaliação de tendências de mudanças nos cursos de graduação das escolas médicas brasileiras. Rio de Janeiro: ABEM, 2006.

BADAN, A. A. F. A et al (Org.). Avaliação institucional na UFG. Goiânia: CEGRAF-UFG, 1997. 
BERTOLIN, J. C. G. Qualidade em Educação Superior: da diversidade de concepções a inexorável subjetividade conceitual. Avaliação, Campinas; Sorocaba, v. 14, n. 1, p. 127-149, 2009.

BRASIL. MINISTÉRIO DA SAÚDE. Pró-Saúde: programa nacional de reorientação da formação profissional em saúde /Ministério da Saúde, Ministério da Educação. Brasília: Ministério da Saúde, 2005.

CECY, C; OLIVEIRA, G. A; COSTA, E. M. M. B. Metodologias ativas: aplicações e vivências em educação farmacêutica. Brasília: Cidade Gráfica e Editora, 2010.

COMISSÃO DE AVALIAÇÃO DAS ESCOLAS MÉDICAS (CAEM). Construção e acompanhamento do processo avaliativo das mudanças nas escolas da área da saúde. Relatório: retorno - escola 99, $2^{\circ}$ momento, 2009.

COSTA, E. M. M. B; RIBEIRO, C. M.; VIEIRA, R. B. B. Avaliação em movimento: do Paiub ao PGE- o caso da Universidade Federal de Goiás. Avaliação, Campinas; Sorocaba, v. 15, n. 3, p. 87-108, mar. 2010.

DIAS SOBRINHO, J. Dilemas da educação superior no mundo globalizado: sociedade do conhecimento ou economia do conhecimento? São Paulo: Casa do Psicólogo, 2005.

HARVEY, L; GREEN, D. Defining Quality. Assessment \& Evaluation in Higher Education, Londres, v. 18, n. 3, p. 9-26, 1993.

LAMPERT, J. B. et al. Projeto de avaliação de tendências de mudanças no curso de graduação nas escolas médicas brasileiras. Rev. Bras. Educ. Med, Rio de Janeiro, v. 33, n. 1, p. 5-18, 2009.

MINAYO, M. C. S. O desafio do conhecimento. Pesquisa qualitativa em saúde. 9. ed. São Paulo: Hucitec, 2006.

MINAYO, M. C. S. Construção de indicadores qualitativos para avaliação de mudanças. Rev. Bras. Educ. Med., Rio de Janeiro, v. 33, n. 1, p. 83-91, 2009 .

RIOS, F. A formação generalista como fator de qualidade. In: CECY, C.; OLIVEIRA, G. A.; COSTA, E. M. M. B. (Orgs.). Melhoria da qualidade em educação farmacêutica. Brasília: Cidade Gráfica e Editora, 2011. 
SEVERINO, A. J. S. Expansão do ensino superior: contextos, desafios, possibilidades. Avaliação, Campinas; Sorocaba, v. 14, n. 2, p. 253-266, 2009.

SINAES - Sistema Nacional de Avaliação da Educação Superior: da concepção a regulamentação. 2. ed. ampl. Instituto Nacional de Estudos e Pesquisas Educacionais Anísio Teixeira, Brasília, 2004.

UNIVERSIDADE FEDERAL DE GOIÁS. Pró-Reitoria de Desenvolvimento Institucional e Recursos Humanos. Avaliação externa dos cursos de graduação - Farmácia. Goiânia: CEGRAF, 1997.

Avaliação Institucional 1998-2001: uma mudança em curso. Goiânia: CEGRAF, 2002.

. Cadernos do Programa de Gestão Estratégica. Caderno $\mathrm{N}^{\circ} 4$ - Os Alunos de Graduação da UFG: Auto Avaliação do Ambiente Acadêmico 2007 - Goiânia: CEGRAF, 2008. 